\title{
Willingness to Participate in Cardiovascular Clinical Research among African- Americans
}

\author{
Patrick S, Xiaotao Z, Stephen G, Stephanie G, Joseph L and Lydia A*
}

Division of Research, Ochsner Health System and the Department of Epidemiology, Tulane University School of Public Health and Tropical Medicine, New Orleans, Louisiana, USA

Corresponding author: Lydia A, Associate Professor of Epidemiology, Tulane University School of Public Health and Tropical Medicine, 1440 Canal St, SL-18, New Orleans, LA, USA; Tel: 504-988-7323; Fax: 504-988-1568; E-mail:Ibazzano@tulane.edu

Received date: May05, 2015; Accepted date: June 27, 2015; Published date: June 30, 2015

Copyright: @ 2015, Lydia A et al. This is an open-access article distributed under the terms of the Creative Commons Attribution License, which permits unrestricted use, distribution, and reproduction in any medium, provided the original author and source are credited.

Key words:

Skepticism; Clinical trials; Cardiovascular Clinical Research

\section{Introduction}

African Americans (AA) have been underrepresented in clinical trials in the United States for a variety of reasons. Barriers to minority enrollment and participation in clinical trials are numerous: patient skepticism, lack of encouragement to enroll, and generally lower health literacy are only a few [1-3]. In cardiovascular clinical research in particular, longer trial durations and intensive tests and procedures were the factors most significantly associated with minority nonparticipation [2]. Many studies examining this issue were conducted more than 10 years ago [4,5] and since then, efforts have been implemented to improve AA enrollment in research [6].

The evidence for some interventions is mixed. Sending targeted letters with individual health risks and ethnic identifiers did not universally improve minority participation in one clinical trial [7]. And yet, improvements in participation have been observed in recent cancer studies. Langford et al. found no differences in clinical trial enrollment by ethnicity in cancer trials between 2009 and 2012 [8]. Attitudes may also have changed among well-educated AA. One study found generally favourable opinions of clinical trials and high willingness to participate among college-educated AA women [9]. Nevertheless, in a review of 445 Gynecologic Oncology Group studies conducted between 1985 and 2013, AA enrollment was 2.8 times lower between the years 2009-2013 as compared to years $1994-2002$ (16\% vs $5.8 \%$, respectively; $\mathrm{p}<0.01$ ), suggesting that AA continue to be underrepresented in many clinical trials despite recent interventions [1]. We took advantage of the cardiovascular research data of a large community academic centre in New Orleans, Louisiana to examine whether willingness to participate in cardiovascular research differed among AA as compared to white individuals.

\section{Methods}

We used a nested, matched case control design with $80 \%$ power to detect a doubling in odds of non-participation. This effect size was considered reasonable based on review of recent studies [1]. Individuals could be included if they were offered participation in any of the 4 largest cardiovascular clinical research studies conducted in 2012, were white or AA and were American citizens ( $n=974)$. Offers of participation were extended to participants in an outpatient medical clinic setting. Participants who failed to provide complete identifying information were excluded. Median household income was inferred using postal codes [10]. Cases were defined as individuals who were offered participation but declined to participate and did not sign a consent form. Controls were defined as individuals who were offered participation and agreed to participate, signing a consent form. We identified 100 cases and selected 200 controls matched on age (within 1 year) and sex using a random selection algorithm. We compared cases and controls using a chi-squared test of independence, and performed conditional logistic regression (SAS version 9.3, Sas Institute Inc) to examine participation by minority status, marital status, employment, household income, family history of cardiovascular disease, smoking status, alcohol consumption, and age. Marital status was categorized as married or unmarried. Employment status was categorized as employed or unemployed/retired. We divided income into groups by the sample median, and by quartiles. Alcohol use was categorized as none or some. Smoking was categorized as current smoker or non-smoker/former smoker. Pvalues $<0.05$ were considered statistically significant, as were two-sided $95 \%$ confidence intervals for odds ratio that did not include 1 .

\section{Results}

Of the 974 eligible individuals, mean (SD) age was 66.7 (12.3) years, median household income in thousands of dollars was 51.9 (19.9), and $65.3 \%$ were men. Of those who agreed to participate, $32.2 \%$ were AA, while of those who declined to participate, $31.0 \%$ were AA. Characteristics of the population by participation status are presented in Table 1. The unadjusted Mantel-Haenszel odds ratio for nonparticipation was 1.06 (95\% confidence interval [CI]: 0.60 to 1.94$)$ for AA individuals compared to their white age and sex matched counterparts. Multivariable-adjusted odds ratios for declining to participate in research are presented by minority status and other characteristics in Table 2. Using multivariable conditional logistic regression, the odds ratio for declining to participate in a study was 1.05 (95\% CI: 0.59 to 1.86 ) for AA as compared to their white age and sex matched counterparts, after adjustment for median household income, employment, marital status, family history, smoking status and alcohol consumption. Odds ratios for non-participation by being AA were consistent in the unadjusted and multivariable adjusted models.

\begin{tabular}{|l|l|l|l|}
\hline Characteristics & Participant & $\begin{array}{l}\text { Non- } \\
\text { participant }\end{array}$ & P-value \\
\hline Age, years & $65.43 \pm 14.41$ & $66.72 \pm 12.36$ & 0.39 \\
\hline Male & 65.29 & 66.67 & 0.78 \\
\hline African-American & 32.2 & 32.3 & 0.99 \\
\hline
\end{tabular}




\begin{tabular}{|l|l|l|l|l|}
\hline $\begin{array}{l}\text { Income, } \\
\text { dollars }\end{array}$ & thousands of & $51.95 \pm 19.90$ & $50.88 \pm 17.83$ & 0.61 \\
\hline
\end{tabular}

Table 1: Characteristics* according to participation status among 974 eligible individuals. ${ }^{*}$ Mean \pm SD for continuous values or $\%$ for categorical values.

\begin{tabular}{|l|l|l|}
\hline Characteristics & Adjusted Odds Ratio & 95\% Confidence Interval \\
\hline African American & 1.05 & $(0.59,1.86)$ \\
\hline Family history of Cardiovascular Disease & 0.70 & $(0.33,1.47)$ \\
\hline Married & 0.98 & $(0.57,1.66)$ \\
\hline Employed & 0.74 & $(0.35,1.55)$ \\
\hline Current smoker & 1.35 & $(0.64,2.84)$ \\
\hline Alcohol consumption & 1.10 & $(0.64,1.90)$ \\
\hline Income above sample median $(\$ 49,440)$ & 0.80 & $(0.47,1.35)$ \\
\hline Age $\geq 60$ years & 0.88 & $(0.47,1.62)$ \\
\hline
\end{tabular}

Table 2:Multivariable-adjusted odds ratio $^{*}$ and $95 \%$ confidence interval from conditional logistic regression for non-participation in research among age and sex-matched cases and controls. ${ }^{\star}$ Multivariable model included adjustment for being AA, family history, marital status, employment status, smoking status, alcohol consumption, income, and age.

\section{Discussion}

Our findings suggest that, at a large community academic centre in the South, being AA does not significantly affect willingness to participate in cardiovascular research independent of age, gender, socioeconomic and marital status. It has been widely assumed that under-representation of AA individuals in research may be due to less willingness to participate as a result of mistrust and fear engendered by scientific ethical misconduct $[4,5]$. However, many studies examining this issue are have been based on community surveys, hypothetical research questionnaires, focus groups, and other instruments rather than participants' actual enrollment decisions. In contrast, a large study conducted in 2006 examined participation in research across a variety of health topics and study designs and found no difference in willingness to participate by minority status [11], suggesting that efforts to increase minority participation in health research should focus on ensuring access to health research for all groups.

Strengths of our study include age and sex matching of cases and controls, and the ability to examine a variety of other factors which may be associated with non-participation including marital status, employment, income and others. Some limitations of our study include the relatively small sample size and lack of information on attitudes towards research. Individual income information that was not available was inferred from postal codes. While this method is used commonly in epidemiologic studies, it is subject to misclassification under a variety of conditions [10]. Our sample was selected from a single large community-academic centre in the South and included only AA and white individuals, thus our results may not be generalizable to other types of research or other minority participants. Furthermore, the white category was not limited to nonHispanic white individuals. We believe these data should help to inform strategies to enhance participation of AA in cardiovascular disease research. Our findings suggest that being AA was not associated with less participation in clinical trials in this setting. Future research should explore minorities to clinical trials in interventions for various diseases, and how to further improve AA participation in clinical research in all settings.

\section{References}

1. Scalici J, Finan M, Black J, Harmon MD, Nicolson W et al. (2015) Minority participation in Gynecologic Oncology Group Studies. Gynecol Oncol S0090-8258: 00932-00934.

2. Martin SS, Ou FS, Newby LK, Sutton V, Adams P, et al. (2013) Patientand trial-specific barriers to participation in cardiovascular randomized clinical trials. J Am Coll Cardiol 61: 762-769.

3. Tanner A, Kim SH, Friedman DB, Foster C, Bergeron CD (2014) Barriers to Medical Research Participation as Perceived by Clinical Trial Investigators: Communicating with Rural and African American Communities. J Health Commun 20: 88-96.

4. Freimuth VS, Quinn SC, Thomas SB, Cole G, Zook E (2001) African Americans' views on research and the Tuskegee Syphilis study. Soc Sci Med 52: 797-808.

5. Corbie G, Thomas SB, Williams MV, Moody S (1999) Participation in Medical Research. J Gen Intern Med 14: 537-546.

6. Branson RD, Davis K, Butler KL (2007) African Americans' participation in clinical research: importance, barriers, and solutions. Am J Surg 193: 32-39.

7. Brown SD, Partee PN, Feng J, Quesenberry CP, Hedderson MM, et al. (2015) Outreach to diversify clinical trial participation: A randomized recruitment study. Clin Trials 12: 205-211.

8. Langford AT, Resnicow K, Dimond EP, Denicoff AM, Germain DS, et al. (2014) Racial/ethnic differences in clinical trial enrollment, refusal rates, ineligibility, and reasons for decline among patients at sites in the National Cancer Institute's Community Cancer Centers Program. Cancer 120: 877-884.

9. Brewer LC, Hayes SN, Parker MW, Balls-Berry JE, Halyard MY, et al (2014) African American Women's Perceptions and Attitudes Regarding Participation in Medical Research: The Mayo Clinic/The Links, Incorporated Partnership. J Women's Heal 23: 681-687. 
Citation: Patrick S, Xiaotao Z, Stephen G, Stephanie G, Joseph L, Lydia A (2015) Willingness to Participate in Cardiovascular Clinical Research among African-Americans. J Clinic Res Bioeth 6: 223. doi:10.4172/2155-9627.1000223

Page 3 of 3

10. Thomas AJ, Eberly LE, Smith GD, Neaton JD (2006) ZIP-code-based versus tract-based income measures as long-term risk-adjusted mortality predictors. Am J Epidemiol 164: 586-590.
11. Wendler D, Kington R, Madans J, Van Wye G, Christ-Schmidt H, et al. Are racial and ethnic minorities less willing to participate in health research? PLoS Med 3: 0201-0210. 